\title{
Kounal of Biomedicine
}

2017; 2: 45-56. doi: 10.7150/jbm.17612

Review

\section{Helicobacter pylori infection: A recent approach to diagnosis and management}

\author{
Ramesh Rana, Sheng Lan Wang, Jing Li, Ying Xin Wang, Qian Wen Rao, Chang Qing Yang ${ }^{凶}$ \\ Division of Gastroenterology and Hepatology, Digestive Disease Institute, Tongji hospital, Tongji University School of Medicine, 389 Xincun \\ road, Shanghai 200065, PR China
}

\begin{abstract}
$\triangle$ Corresponding author: Chang Qing Yang, MD, PhD, Division of Gastroenterology and Hepatology, Digestive Disease Institute, Tongii hospital, Tongji University School of Medicine, 389 Xincun road, Shanghai 200065, PR China. cqyang@tongji.edu.cn Telephone: +86-21-66111604, 13817802801 Fax: +86-21-56050502

(C) Ivyspring International Publisher. This is an open access article distributed under the terms of the Creative Commons Attribution (CC BY-NC) license (https://creativecommons.org/licenses/by-nc/4.0/). See http://ivyspring.com/terms for full terms and conditions.
\end{abstract}

Received: 2016.09.17; Accepted: 2017.01.11; Published: 2017.02.05

\begin{abstract}
Helicobacter pylori infection is the most common infection worldwide and is associated with simple dyspepsia, heartburn and peptic ulcer diseases, most commonly leading to upper gastrointestinal bleeding and, ultimately, to the severe complication of gastric malignancy. Ninety percent of duodenal ulcers and $70 \%$ of gastric ulcers are associated with helicobacter pylori infections. Noninvasive methods, such as the urea breath test (UBT-13C or 14C) and fecal antigen test (FAT), have high sensitivity and specificity for the diagnosis of $\mathrm{H}$. pylori. However, 4-6 weeks of anti-secretary drugs (proton pump inhibitor) prior to testing can lead to false negative results. Invasive methods have benefits over noninvasive methods in the case of peptic ulcer diseases by taking samples for culture to determine their sensitivities and to stage disease progression to malignant transformation. Initially, standard triple regimen was the choice for treatment worldwide. However, high antibiotic resistances in various geographical regions have recently made standard quadruple therapy (bismuth-based) the preferred treatment. Recent studies have shown the promising benefits of 10-14 days of sequential and concomitant quadruple therapies as the first line option in high drug resistance areas, in cases of multidrug resistance or in prior treatment failure cases. Levofloxacin-based triple therapy, furazolidone-based regimens, and recent hybrid or rescue therapies are also beneficial towards the eradication of $\mathrm{H}$. pylori infection as a second or third line therapy. Additionally, the use of probiotics and phytomedicines improve eradication rates when used with triple or quadruple therapies.
\end{abstract}

Key words: Helicobacter pylori, Diagnosis, Treatment, Antibiotic resistance

\section{Introduction}

Helicobacter pylori infection is one of the primary causes of upper gastrointestinal diseases, including dyspepsia, peptic ulcer diseases, heartburn, gastroesophageal reflux disease and even malignant transformation. It is the most common infectious human pathogen, infecting more than $50 \%$ of the populations worldwide (approximately 30\% of children and $60 \%$ of adults), and is associated with $70 \%$ of benign gastric ulcers and $90 \%$ of duodenal ulcers $[1,2]$. The relative risk of gastric cancer in a HP positive group is 1.7-5.3 times higher than that in a HP negative group $[3,4]$. It is more prevalent in developing nations compared to developed nations, indicating that socioeconomic status and living standards may play a major role in the distribution of infection. However, recent data showed a declining prevalence of HP infection in adults (individuals aged $<40$ years) [4, 5]. The global prevalence of $\mathrm{HP}$ infection, according to regions, is the following: 7-30\% in North America, 30-90\% in South America (mostly 
in Chile and Brazil), $1.2-70 \%$ in Europe (least in the Netherlands, $1.2 \%$ ), $13-90 \%$ in Asia (mostly in Bangladesh and India), 50-94\% in the Middle East (mostly in Albania, Bulgaria, and Estonia), $15-20 \%$ in Australia, and 48-95\% in Africa (mostly in Ethiopia) [6]. In China, it is more prevalent in those aged $>60$ years $(86 \%)$ and, surprisingly, is more prevalent in vegetarians [7]. The annual HP re-infection rates in the West are reported to be $0.5-2.5 \%$ compared to $4.3 \%-13 \%$ in Asia [4].

As the eradication of HP infection plays a prime role in reducing the potential risk of complications, such as peptic ulcer disease, MALT lymphoma, and gastric carcinoma, HP eradication therapy performed before 30 years of age has nearly a $100 \%$ chance of preventing gastric cancer. However, the chance of preventing gastric cancer decreases to $41 \%$ in men and $71 \%$ in women when eradication is performed after 70 years of age $[8,9]$. Therefore, the aim of this review is to discuss the recent and appropriate diagnosis and management that are available for $\mathrm{H}$. pylori infections for reducing the lifetime risk of gastric cancers.

\section{Risk factors}

As the volume of drug distribution is higher in obese patients with a high BMI, the risk of drug failure is higher, most likely due to the reduced concentration of drugs at the gastric mucosal level. By contrast, lower basal metabolic index (BMI) patients (especially Asian) will have better outcomes [10]. Smoking is another risk factor for failure of therapy. A meta-analysis showed that the summary odds ratio for eradication failure in smokers versus non-smokers was 1.95 (95\% CI 1.55-2.45), with a corresponding mean difference of $8.4 \%$ in eradication rates. The reason for this finding may be due to reduced gastric blood flow or intragastric $\mathrm{pH}$ in cases of smoking or nicotine, which could potentiate the vacuolating toxin activity of $\mathrm{H}$. pylori in gastric cells $[11,12]$.

\section{Pathogenesis}

Helicobacter pylori, a Gram-negative, helical, rod-shaped bacterium is commonly indwelling in the luminal surface of the gastric epithelium. Typical transmission is via feco-oral or oro-oral routes. Not all infected individuals with $\mathrm{H}$. pylori develop clinical diseases; the reasons for this variation may be bacterial pathogenicity and host susceptibility. Ninety to ninety-five percent of patients with duodenal ulcers and $70 \%$ of those with gastric ulcers are associated with $\mathrm{H}$. pylori infections. Therefore, it is the main cause of peptic ulcer diseases associated with or without upper gastrointestinal bleeding.
Additionally, it is a risk factor for mucosa-associated lymphoid tissue (MALT) lymphoma and gastric adenocarcinoma (mostly noncardia) [13]. Recently, systematic reviews and a meta-analysis revealed that extra gastric diseases are also associated with $\mathrm{H}$. pylori infections, such as unexplained iron deficiency anemia, idiopathic thrombocytopenic purpura, unexplained vitamin B12 deficiency, and the association of CagA-positive HP strains with ischemic heart disease [14]. The pathogenesis of $\mathrm{H}$. pylori includes the following: (i) bacterial colonization in the gastric epithelium (invasion of gastric epithelium); (ii) bacterial virulence factors, including cytotoxin associated gene A (CagA), CagL and type IV secretion system (T4SS), vacuolating cytotoxin A (VacA), and Cag pathogenicity island (PAI) strains (associated with higher inflammatory response); (iii) environmental regulations of virulence factors; (iv) genetic diversity related to virulence; (v) host factors implicated in pathogenesis, including VacA and autophagy, oxidation and antioxidation response, apoptosis, and epigenetic changes, genetics or immune response [15-18]; and (vi) H. pylori colonization in the oral cavity, which significantly correlates with gastroesophageal diseases and could cause re-infection and attenuate the eradication rates of the disease [19].

\section{Diagnosis}

Patients with HP infection may clinically present with dyspepsia, heartburn, abdominal pain, diarrhea, or halitosis. A specific diagnosis can be made by available invasive and non-invasive methods (Table 1). Both methods have good sensitivity and specificity; however, their applicability may vary from country to country.

\section{Invasive methods}

Gastroduodenoscopy is very essential in symptomatic individuals who are not responding to therapy and those aged older than 45 years according to European guidelines [20]. It is not only diagnostic but also therapeutic in upper gastrointestinal bleeding (UGIB) cases. Additionally, it is a very important procedure in taking biopsies to diagnose $\mathrm{H}$. pylori infection using RUT, a histopathological evaluation, culture and sensitivity. These invasive tests have good sensitivity and specificity; however, the chance of false negative results is the drawback that decreases the diagnostic accuracy of this method due to an uneven distribution of $\mathrm{H}$. pylori in the gastric mucosa of the biopsied site and numbers of sampling [4]. 
Table 1. Various diagnostic methods for diagnosis of $\mathrm{H}$. pylori infection

\begin{tabular}{|c|c|c|c|c|c|c|}
\hline \multirow[t]{2}{*}{ Tests } & \multirow[t]{2}{*}{ Sensitivity } & \multirow[t]{2}{*}{ Specificity } & \multicolumn{2}{|c|}{ Diagnosis } & \multirow[t]{2}{*}{ Advantages } & \multirow[t]{2}{*}{ Limitation } \\
\hline & & & Pre-treatment & Post-treatment & & \\
\hline \multicolumn{7}{|l|}{ Non-invasive method: } \\
\hline 13 C-UBT[21, 22, 45, 46] & $95-100 \%$ & $90-100 \%$ & Yes & Yes & $\begin{array}{l}\text { Widely available, reliable, } \\
\text { simple, rapid }\end{array}$ & Special equipment required \\
\hline 14C-UBT & $\begin{array}{l}92 \% \\
\text { PPV-100\% } \\
\text { NPV-84\% }\end{array}$ & $\begin{array}{l}100 \% \\
\text { Accuracy } 94 \%\end{array}$ & Yes & Yes & & May have risk in pregnancy \\
\hline $\begin{array}{l}\text { Monoclonal stool antigen } \\
\text { test (SAT) }[21,22]\end{array}$ & $90-95 \%$ & $90-95 \%$ & Yes & Yes & Simple, reliable, rapid & Low compliance \\
\hline IgG serology 8-14 & $85 \%$ & $80 \%$ & Yes & No & Widely available, simple & Positive in post eradication \\
\hline \multicolumn{7}{|l|}{ Invasive method: } \\
\hline Rapid urease test [21, 22] & $90-95 \%$ & $91-100 \%$ & Yes & Yes & Simple, rapid & High bacterial load \\
\hline Histology $[21,22,27]$ & $90-100 \%$ & $93-99 \%$ & Yes & Yes & Sensitive, secondary diagnostic & Time consuming \\
\hline Immuno-histochemistry & & & Yes & Yes & Excellent sensitivity & Expansive, limited use \\
\hline Culture and sensitivity [31] & $\begin{array}{l}96 \%(\mathrm{MCM}) \\
54 \%(\mathrm{CC})\end{array}$ & $\begin{array}{l}80 \%(\mathrm{MCM}) \\
100 \%(\mathrm{CC})\end{array}$ & No & Yes & Show antibiotic sensitivity & $\begin{array}{l}\text { Limited availability, low } \\
\text { compliance }\end{array}$ \\
\hline PCR [38] & $97 \%$ & $91 \%$ & Yes & Yes & Quick, antibiotic sensitivity & Expansive, limited availability \\
\hline
\end{tabular}

13/14 C-UBT- 13/14 carbon urease breath test, SAT- stool antigen test, PPV- positive predictive value, NPV- negative predictive value, IgG- immunoglobulin G, MCMmicrocapillary culture method, CC- classical culture, PCR- polymerase chain reaction

\section{Rapid urease test (RUT)}

RUT is a biopsy based on a characteristic urease reaction. It is simple and rapid, with very good sensitivity and specificity, even in post-treatment eradication cases. The sensitivity and specificity varies from $90-95 \%$ and $91-100 \%$, respectively [21, 22]. However, the number of bacteria present in the biopsy sample mainly affects the sensitivity of the test [23], and non-helicobacter urease producing organisms (Proteus mirabilis, Citrobacter freundii, Klebsiella pneumonia, Staphylococcus aureus, and Enterobacter cloacae) may cause false-positive results in patients with achlorhydria. Therefore, positive test results after 24 hours should be discarded to rule out false positive test findings [24, 25]. The accuracy of RUT is low, especially in the presence of a gastric hemorrhage compared to SAT. However, gastroduodenoscopy is diagnostic and therapeutic in upper gastrointestinal bleeding, although RUT may not be accurate in the diagnosis of HP-associated upper GI bleeding [4].

\section{Histology}

Histology remains the gold standard for diagnosis of HP gastritis and detection of $\mathrm{H}$. pylori organisms, with a sensitivity and specificity $>95 \%[6$, 21]. Giemsa staining is a widely used technique, and immunostaining would increase the sensitivity and specificity to $100 \%$ and $98-99 \%$, respectively $[5,12$, 26-28]. Furthermore, it is very informative regarding the degree of inflammation and even for categorizing post helicobacter infective gastric mucosal changes (atrophic gastritis, intestinal metaplasia, mucosa associated lymphoid tissue (MALT) lymphoma, malignancy) [28]. A biopsy sample from the body of the stomach is preferred compared to one from the antrum in patients taking acid suppressing drugs, or it can be performed after 2 weeks after drug discontinuation $[5,20]$. The availability of immunohistochemistry is limited; however, it has advantages in diagnosing HP infection in RUT negative cases and HP CagA genotypes [29, 30].

\section{Culture and sensitivity}

The role of culture and sensitivity plays a prime role in increasing $\mathrm{H}$. pylori eradication rates as it not only diagnoses $\mathrm{H}$. pylori infection but also guides clinicians on using the appropriate treatment regimen according to the sensitivities of drugs in particular geographical regions where antibiotic resistance is high. The classical culture method has a lower sensitivity of $65 \%$ compared to the newer microcapillary cultivation method, which has a sensitivity and specificity of $96 \%$ and $80 \%$, respectively [31]. This test is not a common choice in areas where there are lower drug resistances because it is time consuming and expensive, and the availability of the test is limited.

\section{Polymerase chain reactions}

Polymerase chain reaction (PCR) is a recent method of HP diagnosis and targets HP species-specific gene samples taken from blood, saliva, feces or biopsy tissues $[32,33]$. The advantages of PCR are genotyping of HP and detecting antibiotic resistance genes and gene mutations [34-37]. The sensitivity and specificity of this method is $97 \%$ and $91.8 \%$, respectively, even in peptic ulcer disease compared to RUT (47.7\%) and histology (71.6\%) [38]. 
Therefore, it can be diagnostic as well as investigative regarding the choice for appropriate therapeutic drugs. However, the inability to distinguish dead and living HP organisms is the main limitation of this method for confirming eradication. Furthermore, it may give false-positive results by detecting cDNA from non-HP organisms [39, 40].

\section{Non-invasive methods}

\section{Urease breath test: $\left({ }^{13} \mathrm{C}\right.$ and $\left.{ }^{14} \mathrm{C}\right)$}

At present, the urease breath test (UBT) is considered the gold standard method of diagnosing $\mathrm{HP}$ infection in both pre- and post-eradicated cases [2]. There are two carbon isotopes used for UBT: ${ }^{13} \mathrm{C}-$ non-radioactive and ${ }^{14} \mathrm{C}$ - radioactive. Both methods are non-invasive, simple, highly accurate, and comparably expensive, and the ${ }^{13} \mathrm{C}$ UBT is usually not portable. However, the ${ }^{14} \mathrm{C}$ UBT "Heliprobe" is portable and simple, and diagnosis can be made in 20 minutes [41, 42]. Although ${ }^{13} \mathrm{C}$ UBT is a very reliable diagnostic test in children older than 6 years of age, it is unreliable in children below 6 years of age as well as in those who have taken antibiotics or acid suppressing drugs for 2-4 weeks prior to the test [43]. In partial gastrectomy patients, the lateral recombinant position provides a better test result of ${ }^{13} \mathrm{C}$ UBT [44]. The pretreatment ${ }^{13} \mathrm{C}$ UBT dose $(15,25$, $50,100 \mathrm{mg}$ ) has a sensitivity of $96-100 \%$ and specificity of $100 \%$. Furthermore, in post-treatment cases, $15 \mathrm{mg}$ of ${ }^{13} \mathrm{C}$ UBT has a sensitivity and specificity of $100 \%$ and $98.9 \%$, respectively. Therefore, a low dose of 15 $\mathrm{mg}$ of ${ }^{13} \mathrm{C}$ UBT is as equally reliable as $100 \mathrm{mg}[45,46]$. ${ }^{14} \mathrm{C}$ UBT is also the most reliable method of diagnosing HP infection in pre- and post-eradicated cases. The "Heliprobe", a ${ }^{14} \mathrm{C}$ UBT, has a sensitivity, specificity, positive predictive value, negative predictive value, and accuracy of $92 \%, 100 \%, 100 \%$, $84 \%$, and $94 \%$, respectively [42]. As ${ }^{13} \mathrm{C}$ UBT is non-radioactive, it has no radiation hazard, even in pregnancy. However, its non-portability is the main limitation. By contrast, ${ }^{14} \mathrm{C}$ is a radioactive isotope and has little risk of radiation hazard. Therefore, it is not usually recommended during pregnancy.

\section{Fecal/stool antigen test (SAT)}

The stool antigen test has very good diagnostic accuracy in pre- and post-treatment cases of $\mathrm{H}$. pylori infections. A 4-8 week post-treatment evaluation has excellent results; however, an evaluation $<4$ weeks post-treatment after PPI is contradicted [4]. The pre-treatment monoclonal antigen technique performed better than the polyclonal technique in 8 studies (1399 patients), with a sensitivity of $96 \%$ vs $90 \%$, specificity of $97 \%$ vs $94 \%$, PPV of $96 \%$ vs $91 \%$ and NPV of $97 \%$ vs $85 \%$, respectively. Additionally, the monoclonal technique was comparatively better than the polyclonal technique in post-treatment 4-8 weeks after anti-secretary therapy. The sensitivity of SAT declined from $98 \%$ at baseline to $87 \%$ at 7 days and to $83 \%$ at 14 days after PPI treatment [4]. However, monoclonal stool tests are not as reliable as RUT, UBT, and histopathology for diagnosis of $\mathrm{H}$. pylori infections [21].

\section{IgG serology: Serum antigen marker}

IgG antibodies serology is a very simple, widely available test for diagnosis of $\mathrm{H}$. pylori infection. However, its persistence in post-eradicated cases calls into question its use in differentiating acute or past infections or performing post-treatment evaluation. The geographical variation in $\mathrm{H}$. pylori strains can further decrease the reliabilities of the test, although using antigens pooled with different strains would increase its reliability [47, 48]. It may give a false positive test result in a low prevalence population due its low specificity, which has to be confirmed by other reliable tests (SAT or UBT). However, it does not give false negative results in patients taking PPIs or antibiotics or in other clinical circumstances, such as atrophic gastritis, extensive intestinal metaplasia, and MALT. Additionally, particular virulence factors in $\mathrm{H}$. pylori, such as CagA and VacA, can be identified by using specific antibodies serology. As the $\mathrm{H}$. pylori antibody concentrations in saliva and urine are lower than that in serum, these sampling methods are questionable despite being easily obtainable [12, 49]. The serology test is not recommended in children because infected children may not achieve maximal H. pylori specific antibody levels until $7 / 8$ years of age [43].

\section{Management}

The aim of treatment is to eradicate the H. pylori infection; reduce HP related complications, such as atrophic gastritis, peptic ulcer disease, and MALT lymphoma; and reduce the lifetime risk of gastric cancer in individuals with or without a family history, which is the major cause of mortality worldwide. The major indications for eradication in patients with HP positive tests are peptic ulcer disease with or without complications; low-grade gastric mucosa associated lymphoid tissue lymphoma, following resection of gastric cancer; dyspepsia; and patients with first-degree relatives of gastric cancer (Table 2) [4, 6]. Because antibiotic resistance is increasing day by day due to genetic variations or HP strains, the appropriate choice of multidrug regimens plays a prime role in the eradication rates. The factors that are included in choosing appropriate regimens are the prevalence of $\mathrm{HP}$ and gastric cancer, antibiotic 
resistance, drug allergies and tolerances, previous history of treatment and outcomes, cost level, availability of bismuth, adverse effects and patient compliances [6]. The available treatment regimens and their eradication rates are based on intention-to-treat (ITT) and per-protocol (PP) analysis and are given in Table 3.

\section{General measures}

H. pylori infection is more prevalent in lower socioeconomic or developing nations and is transmitted by gut-oral or feco-oral routes. Maintaining good public health measures can play a major role in decreasing its prevalence. Washing hands thoroughly and consuming clean foods and water are additional general measures that should be followed. Eating particular foods, such as broccoli, green tea, and ginger, may have a beneficial effect. Additionally, these general measures only decrease its prevalence, and anti-H. pylori medications are necessary to eradicate infections.
Table 2. Indication for HP eradication

\begin{tabular}{ll}
\hline General recommendation & Strong recommendation \\
\hline Functional dyspepsia & Peptic ulcer disease \\
Chronic gastritis with dyspepsia & Low grade gastric MALT \\
& lymphoma or Gastric MALT \\
& lymphoma
\end{tabular}

Chronic atrophic gastritis with erosion or intestinal metaplasia

Long term use of proton pump inhibitor

Family history of gastric cancer (first degree

relatives with gastric cancer)

After resection of early gastric cancer*

Long term aspirin/ NSAID medication history

with peptic ulcer disease

Idiopathic thrombocytopenic purpura

HP related diseases (gastritis, lymphocytic gastritis, gastric hyperplastic polyps, Menetrier disease, etc.)

Iron deficiency anemia of unknown cause ${ }^{\#}$

Patients' wishes

HP- Helicobacter pylori, MALT- Mucosa associated lymphoid tissue, NSAIDsNonsteroidal anti-inflammatory drugs

*In Korea, post resection of early gastric cancer is a strong recommendation for $\mathrm{HP}$ eradication.

\#In China, iron deficiency anemia of unknown cause is also an indication for HP eradication

Table 3. Treatment regimens and their eradication rates for Helicobacter pylori infections

\begin{tabular}{|c|c|c|c|c|c|}
\hline \multirow[t]{2}{*}{ Drugs } & \multirow{2}{*}{$\begin{array}{l}\text { Treatment } \\
\text { option }\end{array}$} & \multicolumn{2}{|c|}{ Eradication rates } & \multirow[t]{2}{*}{ Advantages } & \multirow[t]{2}{*}{ Limitation } \\
\hline & & ITT (\%) & $\mathrm{PP}(\%)$ & & \\
\hline $\begin{array}{l}\text { Standard therapy } \\
\text { LAC7-14 [61] }\end{array}$ & Standard & 85 & 91 & Widely available & Failure in high resistance \\
\hline $\operatorname{LAL}[63,91]$ & $2^{\text {nd }}-3^{\text {rd }}$ line & $86-96$ & & Alternative if failure of LAC & $\begin{array}{l}\text { Not used in levofloxacin } \\
\text { resistance area }\end{array}$ \\
\hline MAE 7-14 days [50] & $2^{\text {nd }}$ line & $68-75.6$ & 79.9-83.8 & Alternative if Standard therapy failure & Higher resistances \\
\hline \multicolumn{2}{|l|}{$\begin{array}{l}\text { Sequential therapy } \\
\text { LA5+LCM5[61] }\end{array}$} & 87 & 91.6 & & \\
\hline EA5+ELM5 [47] & $2^{\text {nd }}$ line & $\begin{array}{l}95.1 \\
50(+\mathrm{MR}) \\
84(+\mathrm{GM})\end{array}$ & $\begin{array}{l}96.4 \\
97.7(-\mathrm{MR}) \\
95.1(\mathrm{GM})\end{array}$ & No effect of CYP2C19 polymorphism & $\begin{array}{l}\text { Less effective in cases of } \\
\text { resistance }\end{array}$ \\
\hline RA7+RMM7 [64] & $1^{\text {st }}$ line & 91.3 & 93.6 & If bismuth unavailable & \\
\hline RA7+RMC7 [64] & & 71.6 & 75.3 & & \\
\hline OA5+OCT5 & $2^{\text {nd }}$ line & 90 & 94.2 & High resistance area & $19 \% \mathrm{~S} / \mathrm{E}$ \\
\hline PA5+PMC5 [65] & & 89.2 & & High resistance area & \\
\hline \multicolumn{6}{|l|}{ Concomitant therapy } \\
\hline EBTL10[67] & $2^{\text {nd }}$ line & 78.9 & 87 & Amoxicillin allergic cases & \\
\hline EBTM10[67] & $2^{\text {nd }}$ line & 79.7 & 90.8 & Second line in high resistance areas & \\
\hline RRMB10 [73] & $2^{\text {nd }}$ line & 77.7 & 84 & Used in treatment failure cases & \\
\hline PAMC7 [65] & $2^{\text {nd }}$ line & 94.1 & & Alternative to ST, high resistance area & \\
\hline EACM10 [66] & $2^{\text {nd }}$ line & 89.1 & 93.4 & Alternative to ST. & \\
\hline OA7+OCT7 [58] & $2^{\text {nd }}$ line & 82.7 & 95.7 & & \\
\hline \multicolumn{4}{|l|}{ Rescue therapy } & alternative to triple therapy failure & \\
\hline OBAD7 [72] & $3^{\text {rd }}$ line & 91 & 92 & High drug resistance area & \\
\hline RABF7-14 [73] & $3^{\text {rd }}$ line & $89-90$ & $85-90$ & & \\
\hline $\begin{array}{l}\text { VAC7 } \\
\text { VAM7 }[52,53]\end{array}$ & Optional & $\begin{array}{l}89-92 \\
98\end{array}$ & 91 & P-CAB response better than PPI & Limited clinical trial \\
\hline \multicolumn{6}{|c|}{$\begin{array}{l}\text { ITT- intention-to-treat; PP- per protocol; ST- Sequential therapy; LAM14- lansoprazole, amoxicillin, and metronidazole for } 14 \text { days; LA5+LCM5- lansoprazole and amoxicillin } \\
\text { for } 5 \text { days followed by lanzoprazole, clarithromycin, and metronidazole for another } 5 \text { days; EA5+ELM5- esomeprazole and amoxicillin for } 5 \text { days followed by esomeprazole, } \\
\text { levofloxacin, and metronidazole for another } 5 \text { days; (+/-)MR- with/without metronidazole resistance; (+/-) GM- with/without gyrA mutations; OACT- omeprazole, } \\
\text { amoxicillin, clarithromycin, tinidazole; EBTL10- esomeprazole, bismuth subcitrate, tetracycline, and levofloxacin for } 10 \text { days; EBTM10- esomeprazole, bismuth subcitrate, } \\
\text { tetracycline, and metronidazole for } 10 \text { days; RRMB10- rebeprazole, rifabutin, minocycline, and bismuth subcitrate for } 10 \text { days; ELA- ecabet sodium, lansoprazole, amoxicillin } \\
\text { bid for } 2 \text { weeks; OBAD7- omeprazole, bismuth subcitrate, amoxicillin, doxycycline for } 7 \text { days; RABF7-14- rebeprazole, amoxicillin, bismuth subcitrate, furazolidone; VAC7- } \\
\text { vonoprazan, amoxicillin, clarithromycin for } 7 \text { days; VAM7- vonoprazan, amoxicillin, metronidazole for } 7 \text { days }\end{array}$} \\
\hline
\end{tabular}




\section{Antibiotic therapy (Specific therapy)}

\section{Standard therapy}

Standard triple therapy (PPI+ amoxicillin+ clarithromycin) for 7 days is the worldwide followed first line treatment regimen. However, the PPI- based standard therapy fails in up to $30 \%$ of cases due to increased resistance to clarithromycin, subsequently reducing the eradication rate with standard therapy. Therefore, this therapy is usually recommended in low clarithromycin resistant regions. Azithromycin, a worldwide available macrolide, can be used instead; however, cross-resistance decreases the eradication rate. Increasing the duration of therapy to 10 or 14 days is suggested; however, 10 or 14 day use has controversial results and may increase antibiotic resistance [50]. To overcome this issue, sequential, concomitant or quadruple approaches have been alternatively used as a first line therapy [6, 51]. Recently, studies on a triple therapy containing a potassium-competitive acid blocker (P-CAB) (vonoprazan $20 \quad$ mg+amoxicillin $\quad 750$ mg+clarithromycin $200 \mathrm{mg} /$ metronidazole $200 \mathrm{mg}$ bid $^{* 7 d)}$ compared to a PPI-based low dose clarithromycin triple therapy showed promising eradications rates of $89-98 \%[52,53]$. Therefore, P-CAB may be able to replace PPIs as an acid suppressing drug in the future.

Based on published clinical trials, quinolone-containing triple therapy is effective as a first line therapy and can be considered in populations with a clarithromycin resistance $>15 \%$ and quinolone resistance $<10 \%$. Levofloxacin-containing triple therapy has eradication rates ranging from $86-96 \%$, even in retreatment of clarithromycin-based triple therapy non-responders. Although the risk of quinolone resistance with urinary tract infections and respiratory infections is high [54-56], as a second line or third line option, PPI+ amoxicillin and levofloxacin for 10-14 days has significant benefits in eradicating H. pylori infection $[57,58]$.

Standard quadruple therapy is the regimen of choice in the case of standard triple therapy failure and availability of a bismuth subcitrate drug. Quadruple therapy has better eradication rates compared to triple therapy $[12,14]$. The combination of ampicillin-sulbactum (ampicillin $225 \mathrm{mg}$ and sulbactum $150 \mathrm{mg}$ bid.) has equal or higher efficacy in quadruple therapy, so ampicillin-sulbactum can be considered in cases of amoxicillin resistant $\mathrm{H}$. pylori strains [59].

\section{Sequential therapy}

Sequential therapy has significant benefits in eradicating $\mathrm{H}$. pylori infections. There are various regimens that are used for 10-14 days. Commonly used sequential therapies and their eradication rates are presented in Table 3. The eradication rates with these therapies vary from $85-100 \%$. The 10 day therapy has fewer side effects compared to the 14 day therapy, and there are no significant differences in eradication rates [57, 60]. Clarithromycin-based sequential therapy (lansoprazole, amoxicillin bid*5d, followed by lansoprazole, clarithromycin, metronidazole bid*5d) is not superior to 14 days of standard triple therapy in low clarithromycin resistance areas [61]. However, sequential therapy (omeprazole $20 \mathrm{mg}$, amoxicillin $1 \mathrm{gm}$ bid $* \mathrm{~d}$, followed by omeprazole $20 \mathrm{mg}$, clarithromycin $500 \mathrm{mg}$, tinidazole $500 \mathrm{mg} \mathrm{bid}^{*} 5 \mathrm{~d}$ ) demonstrated eradication rates of $91.1 \%$ and $92.1 \%$ according to ITT and PP analyses, respectively, which was significantly better compared to the eradication rates with metronidazole [62]. In a multicenter trial on failed standard triple therapy, sequential therapy (esomeprazole $40 \mathrm{mg}+$ amoxicillin $1 \mathrm{mg}$ bid*5d followed by esomeprazole 40 $\mathrm{mg}+$ levofloxacin $240 \mathrm{mg}+$ metronidazole $500 \mathrm{mg}$ $b^{*}{ }^{*} 5 d$ ) showed a higher eradication rate of $>95 \%$. The eradication rates were significantly higher in the non-metronidazole resistance group $(>97 \%)$ and non-gyrA mutation group (95.1\% vs $84.6 \%)$. Additionally, the CYP2C19 polymorphism did not affect the eradication rates [63]. In comparing moxifloxacin-based (Rebeprazole $20 \mathrm{mg}+$ amoxicillin $1 \mathrm{gm} \mathrm{bid} * \mathrm{~d}$ followed by Rebeprazole $20 \mathrm{mg}+$ metronidazole $500 \mathrm{mg}+$ moxifloxacin $400 \mathrm{mg}$ bid*7d) versus clarithromycin-based sequential therapy, there were significant eradication rates of 91.3/93.6\% (ITT/PP) with moxifloxacin-based therapy. Therefore, it can be very effective as a first line therapy with excellent patient compliance and safety compared to clarithromycin-based sequential therapy (eradication rates of $71.6 / 75.3 \%)$ [64].

\section{Concomitant therapy}

Concomitant therapy is another option for eradicating $\mathrm{H}$. pylori infections in addition to standard therapy and sequential therapy. In these therapies, normally all four drugs are concomitantly given for 7-14 days. They have significant beneficial effects in eradication rates, although the side effects may occur for a longer duration [60]. The various regimens and their efficacies are presented in Table 3. In a multicenter prospective RCT conducted in a high clarithromycin resistant area, concomitant therapy (esomeprazole, $40 \mathrm{mg}$; amoxicillin, $1 \mathrm{mg}$; 
clarithromycin, $500 \mathrm{mg}$; metronidazole, $500 \mathrm{mg}$ bid*10d) had significantly higher eradication rates of $89 \%$ and $93.4 \%$ (versus $78.7 \% / 82.8 \%$ of sequential therapy) according to ITT and PP analyses, respectively, despite drug resistances (metronidazole, $34 \%$; clarithromycin, $27 \%$; and dual drugs ,7.9\%) on culture [9]. In another study, 7 days of concomitant therapy (pantoprazole, $40 \mathrm{mg}$; amoxicillin, $1 \mathrm{mg}$; clarithromycin, $500 \mathrm{mg}$; metronidazole, $500 \mathrm{mg}$ bid) showed eradication rates of $94.1 \%$, which was significantly higher compared to that of 7-day standard triple therapy $(81.6 \%)$ and 10 -day sequential therapy (89.2\%) [65]. Additionally, 7-day concomitant therapy (Rebeprazole, amoxicillin, clarithromycin, metronidazole) showed eradication rates of $90.3 \%$ [57]. In another study with omeprazole, $20 \mathrm{mg}$; amoxicillin, $1 \mathrm{gm}$; clarithromycin, $500 \mathrm{mg}$; and tinidazole, $500 \mathrm{mg}$ for 14 day, the eradication rates were $86.3 \%$ and $95 \%$ according to ITT and PP analyses, respectively [60], whereas the 5-day treatment showed eradication rates of $85.5 \%$ and 91.6\% according to ITT and PP analyses, respectively [62]. Therefore, these therapies with 7-14 day durations can be an alternative to sequential therapy in high drug resistance areas and also in settings where bismuth is not available $[9,57,62,65,66]$.

Ten-day bismuth-based second line quadruple therapies have comparably lower eradication rates. The study with EBTL (esomeprazole, $40 \mathrm{mg}$ bid; bismuth subcitrate, $300 \mathrm{mg}$ qid; tetracycline, $500 \mathrm{mg}$

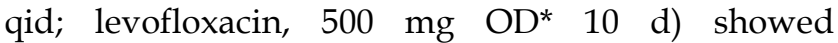
eradication rates of $78.9 \%$ and $87 \%$ according to ITT and PP analyses, respectively [67]. In a high dose metronidazole study, EBTM (esomeprazole, $40 \mathrm{mg}$ bid; bismuth subcitrate, $300 \mathrm{mg}$ qid; tetracycline, 500 mg qid; metronidazole, $500 \mathrm{mg}$ qid*10d) showed eradication rates of $79.7 \%$ and $90.8 \%$ according to ITT and PP analyses, respectively. Metronidazole-based quadruple therapy is cheap, safe and well tolerated. Therefore, this treatment could be an option for second line therapy for $\mathrm{H}$. pylori infections in high resistance areas [67]. A bismuth-based PARB regimen (pantoprazole, amoxicillin, rifabutin, bismuth subcitrate) is the third line quadruple therapy in $\mathrm{H}$. pylori eradication. A study with a PARB regimen (pantoprazole, $20 \mathrm{mg}$; amoxicillin, $1 \mathrm{gm}$; rifabutin, 150 $\mathrm{mg}$; bismuth subcitrate, $240 \mathrm{mg}$ bid) for 10 days demonstrated a significant therapeutic gain, with eradication rates of $96.6 \%$ compared to triple therapy without bismuth subcitrate (66.7\%) [68].

A randomized trial of levofloxacin, $250 \mathrm{mg}$; omeprazole, $20 \mathrm{mg}$; nitazoxanide, $500 \mathrm{mg}$ bid; and doxycycline, $100 \mathrm{mg}$ qd (LOAD) for 7 or 10 days had eradication rates of $88.9 \%$ on LOAD7 and $90 \%$ on
LOAD10. This result demonstrated that the LOAD regimen is highly active in cases of treatment-naïve patients with HP infections. However, further large randomized controlled trials are needed to evaluate the efficacy of this regimen [69]. A meta-analysis showed treatment compared with doxycycline and tetracycline only, and there was no difference in eradication rates; however, compared with other regimens, there were higher eradication rates with doxycycline [70].

\section{Hybrid therapy}

A prospective randomized study with hybrid therapy of omeprazole, $20 \mathrm{mg}$, and amoxicillin, $1 \mathrm{gm}$ twice daily for 7 days, followed by omeprazole, 20 $\mathrm{mg}$; clarithromycin, $500 \mathrm{mg}$; and tinidazole, $500 \mathrm{mg}$ twice daily for another 7 days, showed eradication rates of $82.7 \%$ and $95.7 \%$ according to ITT and PP analyses, respectively. The side effects were comparably less than those of 14-day concomitant therapy $(22.7 \%$ vs. $26.3 \%)$ [60]. Another multicenter pilot study with a hybrid therapy of esomeprazole, 40 $\mathrm{mg}$, and amoxicillin, $1 \mathrm{gm}$, twice daily for 10,12 or 14 days plus clarithromycin, $500 \mathrm{mg}$, and metronidazole, $500 \mathrm{mg}$, twice daily for the final 7 days showed eradication rates of $95 \%, 95.1 \%$, and $93.4 \%$ for the 10 , 12 , and 14 day therapies, respectively. This study concluded that in moderate to low clarithromycin or metronidazole resistance areas, therapy can be shortened to 10 or 12 days. However, further study is essential in moderate to high clarithromycin, metronidazole or dual resistance regions [71].

\section{Rescue therapy}

A study $(\mathrm{n}=74)$ was performed in patients with failed eradication of HP triple therapy (lansoprazole, $30 \mathrm{mg}$; amoxicillin, $750 \mathrm{mg}$; clarithromycin, $200 \mathrm{mg}$ bid) in a Japanese population with rescue therapy (ecabet sodium, $2 \mathrm{gm}$; lansoprazole, $30 \mathrm{mg}$; amoxicillin, $750 \mathrm{mg}$ bid) for 2 weeks. The study demonstrated eradication rates of $75 \%$ and $85.7 \%$ according to ITT and PP analyses, respectively [72]. The anti-HP effect of ecabet sodium has beneficial effects and can be an option for rescue therapy in standard clarithromycin-based triple therapy failure cases.

A rescue quadruple therapy that is tetracycline-based, RRMB (Rebeprazole, rifabutin, minocycline, bismuth subcitrate), in first line triple or sequential therapy and successive levofloxacin-based triple regimen failure cases showed an eradication of $77.7 \%$ and $84 \%$ according to ITT and PP analyses, respectively. This study concluded that a RRMB regimen can be an option in those who have failed at 
least two previous regimens; however, a trial needs to be performed in a larger population [73]. A culture-guided rescue quadruple therapy using omeprazole, bismuth, doxycycline and amoxicillin for 1 week demonstrated eradication rates of $91 \%$ (ITT) and $92 \%$ (PP) despite high drug resistances (metronidazole, 100\%; clarithromycin, 95\%; levofloxacin, 31\%; and tetracycline, 5\%). Therefore, this amoxicillin and doxycycline-based quadruple regimen can be a good third line rescue treatment option [74]. Another rescue trial with furazolidone based quadruple therapy (rebeprazole, $20 \mathrm{mg}$; amoxicillin, $1 \mathrm{gm}$; bismuth subcitrate, $220 \mathrm{mg}$; furazolidone, $100 \mathrm{mg}$ bid ${ }^{*} 14$ days or furazolidone, 100 $\mathrm{mg}$ tid *7 days) had eradications rates of $89 \% / 85 \%$ according to ITT/PP analysis at 14 days and $90 \%$ at 7 days [75].

\section{Alternative therapies}

Probiotics and phytomedicines in Helicobacter pylori infections

Probiotics and phytomedicines are alternative therapies and can reduce antibiotic resistance and increase eradication rates. The most commonly used probiotics are lactic acid producing micro-organisms, such as Lactobacillus spp. and Bifidobacterium spp. Phytomedicines include plant extracts or herbs, ginseng, green tea, red wine, flavonoids, broccoli sprouts, and garlic. The mechanisms of alternative therapies include (i) modulating the host immune response and normal gut microbiota, promoting host health; (ii) decreasing antibiotic associated side-effects; (iii) competing for nutrition and adhesion of cell receptors, leading to reduced colonization of $\mathrm{HP}$; (iv) stimulating mucin production and stabilizing the gut mucosal barrier; and (v) inhibiting the urease enzyme [1, 76-78]. Lactobacillus acidophilus daily

Table 4. Antibiotic resistances according to geographical regions

\begin{tabular}{|c|c|c|c|c|c|c|}
\hline Regions & Metronidazole & Clarithromycin & Amoxicillin & Quinolones & Tetracycline & Furazolidine \\
\hline $\begin{array}{l}\text { Asia[6] }[57,58] \\
\text { Least }\end{array}$ & $27-100 \%$ & $3-45 \%$ & $0-33 \%$ & $3-38 \%$ & $\begin{array}{l}4-7 \% \\
\text { (India) }\end{array}$ & 1-5\% (China) \\
\hline High & $\begin{array}{l}\text { Taiwan } 27 \% \\
\text { SEA 100\% }\end{array}$ & $\begin{array}{l}\text { Thailand 3\% } \\
\text { India } 45 \%\end{array}$ & $\begin{array}{l}\text { Taiwan } 0 \% \\
\text { India 33\% }\end{array}$ & $\begin{array}{l}\text { India 3\% } \\
\text { China } \\
30-38 \%\end{array}$ & China $1-5 \%$ & \\
\hline Europe [56] & $34.9 \%$ & $17.5 \%$ & $0 \%$ & $14.1 \%$ & - & - \\
\hline North America & $44.1 \%$ & $29.3 \%$ & $2.2 \%$ & - & $2.7 \%$ & - \\
\hline South America & $\begin{array}{l}53-82 \% \\
\text { Columbia } 82 \%\end{array}$ & $\begin{array}{l}4-24 \% \\
\text { Argentina 24\% }\end{array}$ & $2 \%$ & - & - & - \\
\hline Africa $[6,82]$ & $\begin{array}{l}55-90 \% \\
\text { (Senegal 90\%) }\end{array}$ & $29.3 \%$ & $65.6 \%$ & - & $43.9 \%$ & - \\
\hline Middle East [6] & $\begin{array}{l}73-100 \% \\
\text { Egypt 100\% }\end{array}$ & $\begin{array}{l}0-9 \% \\
\text { Iran } 9 \%\end{array}$ & $\begin{array}{l}0-21 \% \\
\text { Iran } 21 \%\end{array}$ & $2-5 \%$ & $0-5 \%$ & $9 \%$ (Iran) \\
\hline
\end{tabular}

SEA- Southeast Asia supplementation for two weeks pre- and post-treatment with standard triple therapy (omeprazole+ clarithromycin+ amoxicillin bid) for 7 days demonstrated significantly higher eradication rates at pre-treatment $(79.5 \%)$ and post-treatment $(79.2 \%)$ than without probiotics (60.8\%) [79]. Additionally, meta-analyses on supplementation with probiotics demonstrated comparably higher rates of H. pylori eradication in patients who supplemented with probiotics, and the total side effects (especially diarrhea) were also comparably less with probiotics $[80,81]$.

\section{Antibiotic resistance}

In the present context, increasing antibiotic resistance rates and decreasing eradication rates are the major problems in treating $\mathrm{H}$. pylori infections. The higher rates of clarithromycin resistance in many countries have contradicted its empirical use in standard anti-H. pylori regimens. The overall worldwide resistance rates of metronidazole and clarithromycin are significantly higher followed by levofloxacin compared to other drugs (Table 4) $[6,82]$. Therefore, the culture-guided therapy for $\mathrm{H}$. pylori is currently essential, especially in high antibiotic resistance regions. Based on a European Medicine Agency evaluation of medicinal products that are indicated for the treatment of bacterial infections, 3 categories were defined according to susceptibility to the given antibiotic agents: $0-10 \%$ resistant- usually susceptible, $\quad 10-50 \%$ resistant- inconsistently susceptible, and $>50 \%$ resistant- usually resistant. $\mathrm{H}$. pylori falls into the second category [12]. In European countries, resistance to metronidazole (34.9\%) was higher, followed by $17.5 \%$ with clarithromycin and $14.1 \%$ with levofloxacin. The clarithromycin and levofloxacin resistance rates were significantly higher (> 20\%) in Western, Central and Southern European countries compared to Northern European countries $(<10 \%)$ [83]. In Asian countries, the metronidazole resistances are predominantly higher in Southeast Asian regions $(100 \%)$ and coastal regions of China (>90\%). Amoxicillin (33\%) and clarithromycin $\quad(45 \%)$ resistances are high in India, levofloxacin resistance $(30-38 \%)$ is high in China [6, 84, 85] and gatifloxacin resistance 
$(47.9 \%)$ is high in Japan [86]. In African nations, metronidazole resistances are predominantly high $(92 \%)$, followed by amoxicillin (65\%), tetracycline $(43 \%)$, and clarithromycin $(29 \%)$. In contrast to other geographical regions, amoxicillin and tetracycline resistances are significantly high in African nations [82]. In North American nations, the drug resistance rates were $44 \%$ with metronidazole, followed by clarithromycin $(29 \%)$ and multidrug resistance $(15 \%)$ [82]. In South American nations, metronidazole resistances (Columbia- 82\%) predominated, followed by clarithromycin (Argentina- 24\%) [6]. In Middle Eastern nations, metronidazole resistances (70-100\%) were significantly higher in many countries, followed by amoxicillin $(21 \%)$. In contrast, clarithromycin resistances were lower in these nations (0-9\%) [6]. There were no reports found on the resistances of PPIs, ranitidine, and bismuth $[82,87]$.

\section{Future advances}

In recent years, researchers have improved the understanding of the innate and adaptive immune responses against $\mathrm{H}$. pylori. However, the development of a successful vaccine producing immunity against $\mathrm{H}$. pylori is still uncertain [88]. Anti IL-22 antibody injection efficiently killed $\mathrm{H}$. pylori in an in-vitro mice model. IL-22 played a critical role in vaccine-induced protection by promoting the expression of anti-microbial peptides, including RegIIIB. In conclusion, urease-specific memory Th17/Th22 cells could constitute immune correlates of vaccine protection in humans [89]. In another mouse model, conjugating antigen vaccines with GEM (non-genetically modified Lactococcus lactis) particles could lead to promising oral therapeutic vaccine formulations against $H$. pylori [90].

\section{Conclusion}

As the eradication of $\mathrm{H}$. pylori infection is essential to prevent its ultimate complication, gastric carcinoma, a proper diagnosis can be performed using simple, non-invasive methods, such as UBT and FAT. Eradication can be further improved by testing for drug sensitivities, especially in high drug resistance regions, with the help of invasively biopsied samples for culture and sensitivity. Therefore, appropriate treatment regimens can be conducted according to the geographical regions, even in high drug resistant areas. Recently, clarithromycin-based standard triple therapy has become not recommended in high drug resistant regions; instead, bismuth containing quadruple therapy is preferred. Currently, sequential or concomitant quadruple therapies have significant higher eradication rates even in single or multiple drug resistant cases; therefore, these treatments can be recommended in standard triple therapy failure or if there is a contraindication to bismuth containing quadruple therapy. Additionally, probiotics and phytomedicines in addition to triple or quadruple/sequential/concomitant therapies would not only improve the eradication rates but also decrease the antibiotic resistance rates.

\section{Abbreviations}

HP: Helicobacter pylori; RUT: Rapid urease test; UBT: Urease breath test; SAT: Stool antigen test; RUT: Rapid urease test; IgG: Immunoglobulin G; BMI: Basal metabolic index; CagA: Cytotoxin-associated antigen A, T4SS: type IV secretion system; VacA: Vacuolating cytotoxin A; PAI: Cag pathogenicity island (PAI) strains; MALT: Mucosa associated lymphoid tissue lymphoma; PCR: Polymerase chain reaction; ITT: Intention-to-treat; PP: Per-protocol; vs: versus; CI: confidence interval; UGIB: Upper gastrointestinal bleeding; cDNA: circulating deoxyribonucleic acid; 13 C: 13 carbon isotope; ${ }^{14} \mathrm{C}$ : 14 carbon isotope; PPIs: Proton pump inhibitors; P-CAB: Potassium competitive acid blocker; CYP2C19: Cytochrome P450 2C19; RCT: Randomized control trial; EBTL: Esomeprazole, bismuth subcitrate, tetracycline, levofloxacin; EBTM: Esomeprazole, bismuth subcitrate, tetracycline, metronidazole; PARB: Pantoprazole, amoxicillin, rifabutin, bismuth subcitrate; LOAD 7 or 10: Levofloxacin, omeprazole, nitazoxanide, doxycycline for 7 or 10 days; RRMB: Rebeprazole, rifabutin, minocycline, bismuth subcitrate; GEM: non-genetically modified Lactococcus lactis.

\section{Acknowledgements}

Funding: This study was supported by grants from the National Natural Science Foundation of China (No. 81370559), Shanghai major joint project for important diseases (2014ZYJB0201), and Shanghai joint project with advanced technology (SHDC12014122).

\section{Competing Interests}

The authors have declared that no competing interest exists.

\section{References}

1. Vítor JM, Vale FF. Alternative therapies for Helicobacter pylori: probiotics and phytomedicine. FEMS Immunology \& Medical Microbiology. 2011; 63: 153-64. doi:10.1111/j.1574-695X.2011.00865.x.

2. Choi YJ. Specific Conditions: Diagnosis of H. pylori Infection in Case of Upper Gastrointestinal Bleeding. Helicobacter pylori: Springer; 2016: 157-62. 
3. Helicobacter, Group CC. Gastric cancer and Helicobacter pylori: a combined analysis of 12 case control studies nested within prospective cohorts. Gut. 2001; 49: 347-53.

4. Kim SG, Jung HK, Lee HL, Jang JY, Lee H, Kim CG, et al. Guidelines for the diagnosis and treatment of Helicobacter pylori infection in Korea. Journal of gastroenterology and hepatology. 2014; 29: 1371-86. doi:10.1111/jgh.12607

5. Tonkic A, Tonkic M, Lehours P, Mégraud F. Epidemiology and diagnosis of Helicobacter pylori infection. Helicobacter. 2012; 17: 1-8. doi: 10.1111/j.1523- 5378.2012.00975.x.

6. Hunt R, Xiao S, Megraud F, Leon-Barua R, Bazzoli F, Van Der Merwe S, et al. Helicobacter pylori in developing countries. World gastroenterology organisation global guideline. Journal of gastrointestinal and liver disease. 2011; 20: 299-304.

7. Zhang M, Zhou Y-Z, Li X-Y, Tang Z, Zhu H-M, Yang Y, et al. Seroepidemiology of Helicobacter pylori infection in elderly people in the Beijing region, China. World journal of gastroenterology: WJG. 2014; 20: 3635. doi: 10.3748 /wjg.v20.i13.3635.

8. Kato M, Asaka M. Recent knowledge of the relationship between Helicobacter pylori and gastric cancer and recent progress of gastroendoscopic diagnosis and treatment for gastric cancer. Japanese journal of clinical oncology. 2010; 40: 828-37. doi: 10.1093/jjco/hyq119.

9. Lee S-Y. Current progress toward eradicating Helicobacter pylori in East Asian countries: differences in the 2013 revised guidelines between China, Japan, and South Korea. World journal of gastroenterology. 2014; 20: 1493-502. doi:10.3748/wjg.v20.i6.1493.

10. Abdullahi M, Annibale B, Capoccia D, Tari R, Lahner E, Osborn J, et al. The eradication of Helicobacter pylori is affected by body mass index (BMI). Obesity surgery. 2008; 18: 1450-4. doi: 10.1007/s11695-008-9477-z.

11. Suzuki T, Matsuo K, Ito H, Sawaki A, Hirose K, Wakai K, et al. Smoking increases the treatment failure for Helicobacter pylori eradication. The American journal of medicine. 2006; 119: 217-24. doi: 10.1016/j.amjmed.2005.10.003.

12. Malfertheiner P, Megraud F, O'Morain CA, Atherton J, Axon AT, Bazzoli F, et al. Management of Helicobacter pylori infection - the Maastricht IV/Florence consensus report. Gut. 2012; 61: 646-64. doi:10.1136/gutjnl-2012-302084.

13. Ekström AM, Held M, Hansson L-E, Engstrand L, Nyrén O. Helicobacter pylori in gastric cancer established by CagA immunoblot as a marker of past infection. Gastroenterology. 2001; 121: 784-91.

14. Zagari RM, Romano M, Ojetti V, Stockbrugger R, Gullini S, Annibale B, et al. Guidelines for the management of Helicobacter pylori infection in Italy: the III Working Group Consensus Report 2015. Digestive and Liver Disease. 2015; 47: 903- $\quad$ 12. doi: 10.1016/j.dld.2015.06.010.

15. Cid TP, Fernández MC, Benito Martínez S, Jones NL. Pathogenesis of Helicobacter pylori infection. Helicobacter. 2013; 18: 12-7. doi: 10.1111/hel.12076.

16. Figueiredo C, Machado JC, Yamaoka Y. Pathogenesis of Helicobacter pylori infection. Helicobacter. 2005; 10: 14-20. doi: 10.1111/j.1523-5378.2005.00339.x.

17. Costa AC, Figueiredo C, Touati E. Pathogenesis of Helicobacter pylori infection. Helicobacter. 2009; 14: 15-20. doi: 10.1111/j.1523-5378.2009.00702.x.

18. Backert S, Clyne M. Pathogenesis of Helicobacter pylori infection. Helicobacter. 2011; 16: 19-25. doi:10.1111/j.1523-5378.2011.00876.x.

19. Zou QH, Li RQ. Helicobacter pylori in the oral cavity and gastric mucosa: a meta-analysis. Journal of Oral Pathology \& Medicine. 2011; 40: 317-24. doi: 10.1111/j.1600-0714.2011.01006.x.

20. Mentis A, Lehours P, Mégraud F. Epidemiology and Diagnosis of Helicobacter pylori infection. Helicobacter. 2015; 20: 1-7. doi: 10.1111/hel.12250.

21. Lario S, Ramirez-Lazaro MJ, Montserrat A, Quilez ME, Junquera F, Martinez-Bauer E, et al. Diagnostic accuracy of three monoclonal stool tests in a large series of untreated Helicobacter pylori infected patients. $\begin{array}{llll}\text { Clinical } & \text { biochemistry. } & \text { 2016; } & \end{array}$ doi:10.1016/j.clinbiochem.2016.01.015.

22. Calvet X, Sánchez-Delgado J, Montserrat A, Lario S, Ramírez-Lázaro MJ, Quesada M, et al. Accuracy of diagnostic tests for Helicobacter pylori: a reappraisal. Clinical Infectious Diseases. 2009; 48: 1385-91. doi: 10.1086/598198.

23. Vaira D, Gatta L, Ricci C, Miglioli M. Diagnosis of Helicobacter pylori infection. Alimentary pharmacology \& therapeutics. 2002; 16: 16-23.

24. Ferwana M, Abdulmajeed I, Alhajiahmed A, Madani W, Firwana B, Hasan R, et al. Accuracy of urea breath test in Helicobacter pylori infection: Meta-analysis. World journal of gastroenterology: WJG. 2015; 21: 1305-14. doi: 10.3748/wjg.v21.i4.1305.
25. Osaki T, Mabe K, Hanawa T, Kamiya S. Urease-positive bacteria in the stomach induce a false-positive reaction in a urea breath test for diagnosis of Helicobacter pylori infection. Journal of medical microbiology. 2008; 57: 814-9. doi: 10.1099/jmm.0.47768-0.

26. Braden B. Diagnosis of Helicobacter pylori infection. BMJ (Clinical research ed). 2012; 344: e828. doi: 10.1136/bmj.e828.

27. Buharideen S, Wijetunge $S$, Jayamaha $T$, Sinnadurei A, Waduge $R$, Ratnatunga C. Evaluation of histology as a Helicobacter pylori detection method and analysis of associated problems. Journal of Diagnostic Pathology. 2016; 10: 2. doi: 10.4038/jdp.v10i2.7676.

28. Lee HS. Histopathologic Diagnosis of H. pylori Infection and Associated Gastric Diseases. Helicobacter pylori: Springer; 2016: 119-27.

29. Eshun JK, Black DD, Casteel HB, Horn H, Beavers-May T, Jetton CA, et al. Comparison of immunohistochemistry and silver stain for the diagnosis of pediatric Helicobacter pylori infection in urease-negative gastric biopsies. Pediatric and Developmental Pathology. 2001; 4: 82-8.

30. Uchida T, Kanada R, Tsukamoto Y, Hijiya N, Matsuura K, Yano S, et al. Immunohistochemical diagnosis of the cagA-gene genotype of Helicobacter pylori with anti-East Asian CagA-specific antibody. Cancer science. 2007; 98: 521-8. doi: 10.1111/j.1349-7006.2007.00415.x.

31. Allahverdiyev AM, Bagirova M, Caliskan R, Tokman HB, Aliyeva H, Unal $G$, et al. Isolation and diagnosis of Helicobacter pylori by a new method: microcapillary culture. World J Gastroenterol. 2015; 21: 2622-8262. doi: 10.3748/wjg.v21.i9.2622.

32. Nagasawa S, Azuma T, Motani H, Sato Y, Hayakawa M, Yajima D, et al. Detection of Helicobacter pylori (H. pylori) DNA in digestive systems from cadavers by real- time PCR. Legal Medicine. 2009; 11: S458-S9. doi: 10.1016/j.legalmed.2009.03.001.

33. Kabir S. Detection of Helicobacter pylori DNA in feces and saliva by polymerase chain reaction: a review. Helicobacter. 2004; 9: 115-23. doi: 10.1111/j.1083-4389.2004.00207.x.

34. Glocker E, Kist M. Rapid detection of point mutations in the gyrA gene of Helicobacter pylori conferring resistance to ciprofloxacin by a fluorescence resonance energy transfer-based real-time PCR approach. Journal of clinical microbiology. 2004; 42: 2241-6.

35. Oleastro M, Ménard A, Santos A, Lamouliatte H, Monteiro L, Barthélémy $\mathrm{P}$, et al. Real-time PCR assay for rapid and accurate detection of point mutations conferring resistance to clarithromycin in Helicobacter pylori. Journal of clinical microbiology. 2003; 41: 397-402.

36. Oleastro M, Gerhard M, Lopes A, Ramalho P, Cabral J, Guerreiro AS, et al. Helicobacter pylori virulence genotypes in Portuguese children and adults with gastroduodenal pathology. European Journal of Clinical Microbiology and Infectious Diseases. 2003; 22: 85-91. doi: 10.1007/s10096-002-0865-3.

37. Ribeiro ML, Gerrits MM, Benvengo YH, Berning M, Godoy AP, Kuipers EJ, et al. Detection of high-level tetracycline resistance in clinical isolates of Helicobacter pylori using PCR-RFLP. FEMS Immunology \& Medical Microbiology. 2004; 40: 57-61.

38. Chung WC, Jeon EJ, Oh JH, Park JM, Kim TH, Cheung DY, et al. Dual-priming oligonucleotide-based multiplex PCR using tissue samples from the rapid urease test kit for the detection of Helicobacter pylori in bleeding peptic ulcers. Digestive and Liver Disease. 2016; 48: 899-903. doi: 10.1016/j.dld.2016.04.012.

39. Sugimoto M, Wu J-Y, Abudayyeh S, Hoffman J, Brahem H, Al-Khatib K, et al. Unreliability of results of PCR detection of Helicobacter pylori in clinical or environmental samples. Journal of clinical microbiology. 2009; 47: 738-42. doi: 10.1128/JCM.01563-08.

40. Wang S, Zhang W-M, Reineks E. Breath Tests for Detection of Helicobacter pylori and Aspergillus fumigatus. Advanced Techniques in Diagnostic Microbiology: Springer; 2013: 13-30.

41. Parente F, Porro GB. The 13C-urea breath test for non-invasive diagnosis of Helicobacter pylori infection: which procedure and which measuring equipment? European journal of gastroenterology \& hepatology. 2001; 13: 803-6.

42. Jonaitis LV, Kiudelis G, Kupcinskas L. Evaluation of a novel 14C-urea breath test" Heliprobe" in diagnosis of Helicobacter pylori infection. Medicina (Kaunas, Lithuania). 2007; 43: 32-5.

43. Drumm B, Koletzko S, Oderda G, pylori EPTFoH. Helicobacter pylori infection in children: a consensus statement. Journal of pediatric gastroenterology and nutrition. 2000; 30: 207-13.

44. Yin SM, Zhang F, Shi DM, Xiang P, Xiao L, Huang YQ, et al. Effect of posture on C- 13-urea breath test in partial gastrectomy patients. World Journal of Gastroenterology. 2015; 21: 12888-95. doi: 10.3748/wjg.v21.i45.12888

45. Gatta L, Ricci C, Tampieri A, Osborn J, Perna F, Bernabucci V, et al. Accuracy of breath tests using low doses of 13C-urea to diagnose 
Helicobacter pylori infection: a randomised controlled trial. Gut. 2006; 55: 457-62. doi: 10.1136/gut.2005.078626.

46. Gatta L, Vakil N, Ricci C, Osborn J, Tampieri A, Perna F, et al. A rapid, low-dose, 13C-urea tablet for the detection of Helicobacter pylori infection before and after treatment. Alimentary pharmacology \& therapeutics. 2003; 17: 793-8.

47. Marchildon PA, Sugiyama T, Fukada Y, Peacock JS, Asaka M, Shimoyama T, et al. Evaluation of the effects of strain-specific antigen variation on the accuracy of serologic diagnosis of Helicobacter pylori infection. Journal of clinical microbiology. 2003; 41: 1480-5.

48. Atkinson NSS, Braden B. Helicobacter Pylori Infection: Diagnostic Strategies in Primary Diagnosis and After Therapy. Digestive Diseases and Sciences. 2016; 61: 19- 24. doi: 10.1007/s10620-015-3877-4.

49. Leodolter A, Vaira D, Bazzoli F, Schütze K, Hirschl A, Megraud F, et al. European multicentre validation trial of two new non-invasive tests for the detection of Helicobacter pylori antibodies: urine-based ELISA and rapid urine test. Alimentary pharmacology \& therapeutics. 2003; 18: 927-31.

50. Yoon H, Kim N, Lee BH, Hwang TJ, Lee DH, Park YS, et al. Moxifloxacin- Containing Triple Therapy as Second-Line Treatment for Helicobacter pylori Infection: Effect of Treatment Duration and Antibiotic Resistance on the Eradication Rate. Helicobacter. 2009; 14: 429-37. doi: 10.1111/j.1523-5378.2009.00709.x.

51. Mégraud F. The challenge of Helicobacter pylori resistance to antibiotics: the comeback of bismuth-based quadruple therapy. Therapeutic advances in gastroenterology. 2012; 5: 103-9. doi: $10.1177 / 1756283 \times 11432492$.

52. Suzuki S, Gotoda T, Kusano C, Iwatsuka K, Moriyama M. The Efficacy and Tolerability of a Triple Therapy Containing a Potassium-Competitive Acid Blocker Compared With a 7-Day PPI-Based Low-Dose Clarithromycin Triple Therapy. The American journal of gastroenterology. 2016; 111: 949-56. doi: 10.1038/ajg.2016.182.

53. Murakami K, Sakurai Y, Shiino M, Funao N, Nishimura A, Asaka M. Vonoprazan, a novel potassium-competitive acid blocker, as a component of first-line and second- line triple therapy for Helicobacter pylori eradication: a phase III, randomised, double-blind study. Gut. 2016; doi: 10.1136/gutjnl-2015-311304.

54. Berning M, Krasz S, Miehlke S. Should quinolones come first in Helicobacter pylori therapy? Therapeutic advances in gastroenterology. 2010; 4:103-4. doi: 10.1177/1756283X10384171.

55. Federico A, Gravina AG, Miranda A, Loguercio C, Romano M. Eradication of Helicobacter pylori infection: which regimen first. World journal of gastroenterology. 2014; 20: 665-72. doi: 10.3748/wjg.v20.i3.665.

56. Lee YC, Wu HM, Chen THH, Liu TY, Chiu HM, Chang CC, et al. A Community-Based Study of Helicobacter pylori Therapy Using the Strategy of Test, Treat, Retest, and Re-treat Initial Treatment Failures. Helicobacter. 2006; 11: 418-24. doi: 10.1111/j.1523-5378.2006.00432.x.

57. Jung SM, Cheung DY, Kim JI, Kim I, Seong H. Comparing the Efficacy of Concomitant Therapy with Sequential Therapy as the First-Line Therapy of Helicobacter pylori Eradication. Gastroenterology research and practice. 2016: 5. doi: 10.1155/2016/1293649.

58. Li BZ, Threapleton DE, Wang JY, Xu JM, Yuan JQ, Zhang C, et al. Comparative effectiveness tolerance of treatments for Helicobacter pylori: systematic review and network meta-analysis. BMJ (Clinical research ed). 2015; 351: h4052. doi: 10.1136/bmj.h4052.

59. Mirbagheri SA, Hasibi M, Abouzari M, Rashidi A. Triple, standard quadruple and ampicillin-sulbactam-based quadruple therapies for $\mathrm{H}$ pylori eradication: A comparative three-armed randomized clinical trial. World journal of gastroenterology. 2006; 12: 4888.

60. De Francesco V, Hassan C, Ridola L, Giorgio F, Ierardi E, Zullo A. Sequential, concomitant and hybrid first-line therapies for Helicobacter pylori eradication: a prospective randomized study. Journal of medical microbiology. 2014; 63: 748-52. doi: 10.1099/jmm.0.072322-0.

61. Liou J-M, Chen C-C, Chen M-J, Chen C-C, Chang C-Y, Fang Y-J, et al. Sequential versus triple therapy for the first-line treatment of Helicobacter pylori: a multicentre, open-label, randomised trial. Lancet. 2013; 381: 205-13. doi: 10.1016/S0140- 6736(12)61579-7.

62. Zullo A, Scaccianoce G, De Francesco V, Ruggiero V, D'Ambrosio P, Castorani $\mathrm{L}$, et al. Concomitant, sequential, and hybrid therapy for $\mathrm{H}$. pylori eradication: a pilot study. Clinics and research in hepatology and gastroenterology. 2013; 37: 647-50. doi: 10.1016/j.clinre.2013.04.003.

63. Liou JM, Chen CC, Chen MJ, Chang CY, Fang YJ, Lee JY, et al. Empirical modified sequential therapy containing levofloxacin and high-dose esomeprazole in second-line therapy for Helicobacter pylori infection: a multicentre clinical trial. The Journal of antimicrobial chemotherapy. 2011; 66: 1847-52. doi: 10.1093/jac/dkr217.
64. Hwang JJ, Lee DH, Lee AR, Yoon H, Shin CM, Park YS, et al. Efficacy of moxifloxacin-based sequential therapy for first-line eradication of Helicobacter pylori infection in gastrointestinal disease. World journal of gastroenterology. 2015; 21: 5032-8. doi: 10.3748/wjg.v21.i16.5032.

65. Hsu P-I, Wu D-C, Chen W-C, Tseng H-H, Yu H-C, Wang H-M, et al. Randomized controlled trial comparing 7-day triple, 10-day sequential, and 7-day concomitant therapies for Helicobacter pylori infection. Antimicrobial agents and chemotherapy. 2014; 58: 5936-42. doi: 10.1128/AAC.02922-14.

66. Georgopoulos SD, Xirouchakis E, Martinez-Gonzales B, Zampeli E, Grivas E, Spiliadi C, et al. Randomized clinical trial comparing ten day concomitant and sequential therapies for Helicobacter pylori eradication in a high clarithromycin resistance area. European journal of internal medicine. 2016;32:84-90. doi: 10.1016/j.ejim.2016.04.011.

67. Kuo CH, Hsu PI, Kuo FC, Wang SS, Hu HM, Liu CJ, et al. Comparison of 10 day bismuth quadruple therapy with high-dose metronidazole or levofloxacin for second- line Helicobacter pylori therapy: a randomized controlled trial. The Journal of antimicrobial chemotherapy. 2013; 68: 222-8. doi:10.1093/jac/dks361.

68. Ciccaglione AF, Tavani R, Grossi L, Cellini L, Manzoli L, Marzio L. Rifabutin Containing Triple Therapy and Rifabutin with Bismuth Containing Quadruple Therapy for Third-Line Treatment of Helicobacter pylori Infection: Two Pilot Studies. Helicobacter. 2016;21:375-81. doi: 10.1111/hel.12296.

69. Basu PP, Rayapudi K, Pacana T, Shah NJ, Krishnaswamy N, Flynn M. A randomized study comparing levofloxacin, omeprazole, nitazoxanide, and doxycycline versus triple therapy for the eradication of Helicobacter pylori. The American journal of gastroenterology. 2011; 106: 1970-5. doi: 10.1038/ajg.2011.306

70. Niv Y. Doxycycline in Eradication Therapy of Helicobacter pylori-A Systematic Review and Meta-Analysis. Digestion. 2016; 93: 167-73. doi: $10.1159 / 000443683$.

71. Wu JY, Hsu PI, Wu DC, Graham DY, Wang WM. Feasibility of Shortening 14-day Hybrid Therapy While Maintaining an Excellent Helicobacter pylori Eradication Rate. Helicobacter. 2014; 19: 207-13. doi: 10.1111/hel.12113.

72. Furuta T, Kato M, Sugimoto M, Sasaki M, Kamoshida T, Furukawa K, et al. Triple therapy with ecabet sodium, amoxicillin and lansoprazole for 2 weeks as the rescue regimen for $\mathrm{H}$. pylori infection. Internal medicine (Tokyo, Japan). 2011; 50: 369-74.

73. Ierardi E, Giangaspero A, Losurdo G, Giorgio F, Amoruso A, De Francesco V, et al. Quadruple rescue therapy after first and second line failure for Helicobacter pylori treatment: comparison between two tetracycline-based regimens. J Gastrointestin Liver Dis. 2014; 23: 367-70. doi: 10.15403/jgld.2014.1121.234.qrth.

74. Cammarota G, Martino A, Pirozzi G, Cianci R, Branca G, Nista E, et al. High efficacy of 1-week doxycycline-and amoxicillin-based quadruple regimen in a culture-guided, third-line treatment approach for Helicobacter pylori infection. Alimentary pharmacology \& therapeutics. 2004; 19: 789-95. doi: 10.1111/j.1365-2036.2004.01910.x.

75. Cheng H, Hu F-L. Furazolidone, amoxicillin, bismuth and rabeprazole quadruple rescue therapy for the eradication of Helicobacter pylori. World Journal of gastroenterology. 2009; 15: 860-4.

76. Vale FF, Vítor JM, Oleastro M. Probiotics as an Alternative Therapy for Helicobacter pylori-Associated Diseases. Helicobacter pylori Research: Springer; 2016: 543-74.

77. Hwang SW. Probiotics. Helicobacter pylori: Springer; 2016: 479-85.

78. de Klerk N, Maudsdotter L, Gebreegziabher H, Saroj SD, Eriksson B, Eriksson OS, et al. Lactobacilli reduce Helicobacter pylori attachment to host gastric epithelial cells by inhibiting adhesion gene expression. Infection and immunity. 2016; 84: 1526-35, doi: 10.1128/IAI.00163-16.

79. Du YQ, Su T, Fan JG, Lu YX, Zheng P, Li XH, et al. Adjuvant probiotics improve the eradication effect of triple therapy for Helicobacter pylori infection. World Journal of Gastroenterology. 2012; 18: 6302-7. doi: 10.3748/wjg.v18.i43.6302

80. Tong J, Ran Z, Shen J, Zhang C, Xiao S. Meta-analysis: the effect of supplementation with probiotics on eradication rates and adverse events during Helicobacter pylori eradication therapy. Alimentary pharmacology \& therapeutics. 2007; 25: 155-68. doi: 10.1111/j.1365-2036.2006.03179.x.

81. Zou J, Dong J, Yu XF. Meta-Analysis: The Effect of Supplementation with Lactoferrin on Eradication Rates and Adverse Events During Helicobacter pylori Eradication Therapy. Helicobacter. 2009; 14: 119-27. doi: 10.1111/j.1523-5378.2009.00666.x.

82. De Francesco V, Giorgio F, Hassan C, Manes G, Vannella L, Panella C, et al. Worldwide $\mathrm{H}$. pylori antibiotic resistance: a systematic review. Journal of gastrointestinal and liver disease. 2010; 19: 409-14. 
83. Megraud F, Coenen S, Versporten A, Kist M, Lopez-Brea M, Hirschl AM, et al. Helicobacter pylori resistance to antibiotics in Europe and its relationship to antibiotic consumption. Gut. 2013; 62: 34-42. doi: 10.1136/gutjnl-2012-302254.

84. Sun Q-J, Liang X, Zheng Q, Gu W-Q, Liu W-Z, Xiao S-D, et al. Resistance of Helicobacter pylori to antibiotics from 2000 to 2009 in Shanghai. World journal of gastroenterology. 2010; 16: 5118-21.

85. Su P, Li Y, Li H, Zhang J, Lin L, Wang Q, et al. Antibiotic resistance of Helicobacter pylori isolated in the Southeast Coastal Region of China. Helicobacter. 2013; 18: 274-9. doi: 10.1111/hel.12046.

86. Nishizawa T, Suzuki H, Hibi T. Quinolone-based third-line therapy for Helicobacter pylori eradication. Journal of clinical biochemistry and nutrition. 2009; 44: 119-24. doi: 10.3164/jcbn.08-220R.

87. Gerrits MM, van Vliet AH, Kuipers EJ, Kusters JG. Helicobacter pylori and antimicrobial resistance: molecular mechanisms and clinical implications. The Lancet infectious diseases. 2006; 6: 699-709. doi: 10.1016/S1473-3099(06)70627-2

88. Koch M, Meyer TF, Moss SF. Inflammation, immunity, vaccines for Helicobacter pylori infection. Helicobacter. 2013; 18: 18-23. doi: 10.1111/hel.12073.
89. Moyat M, Bouzourene H, Ouyang W, Iovanna J, Renauld J, Velin D. IL-22-induced antimicrobial peptides are key determinants of mucosal vaccine-induced protection against $H$. pylori in mice. Mucosal immunology. 2016;4. doi: 10.1038/mi.2016.38.

90. Liu W, Tan Z, Xue J, Luo W, Song H, Lv X, et al. Therapeutic efficacy of oral immunization with a non-genetically modified Lactococcus lactis-based vaccine CUE-GEM induces local immunity against Helicobacter pylori infection. Applied microbiology and biotechnology. 2016: 1-11. doi: 10.1007/s00253-016-7333-y.

91. Liou J-M, Lin J-T, Chang C-Y, Chen M-J, Cheng T-Y, Lee Y-C, et al. Levofloxacin- based and clarithromycin-based triple therapies as first-line and second-line treatments for Helicobacter pylori infection: a randomised comparative trial with crossover design. Gut. 2010; 59: 572-8. doi: 10.1136/gut.2009.198309.

92. Kuo CH, Lu CY, Shih HY, Liu CJ, Wu MC, Hu HM, et al. CYP2C19 polymorphism influences Helicobacter pylori eradication. World journal of gastroenterology. 2014; 20: 16029-36. doi: 10.3748/wjg.v20.i43.16029. 